\title{
PENERAPAN PEMBERIAN LATIHAN SOAL-SOAL KONTEKSTUAL DALAM MENINGKATKAN HASIL BELAJAR MATEMATIKA
}

\author{
A. Purwantoro,,$^{1, a}$ Drs. B. Saryantono, M.M ${ }^{2 . b}$ \\ ${ }^{2}$ Sarjana Pendidikan Matematika, FKIP, STKIP-PGRI Bandar Lampung, \\ Jl. Chairil Anwar, Durian Payung, Kec. Tj. Karang Pusat, Kota Bandar Lampung \\ e-mail: ${ }^{a}$ aguspurwantoro@gmail.com, b bguangsaryantono@yahoo.co.id
}

\begin{abstract}
The learning process involves three important components, namely subject matter, learning activities and assessment (evaluation). Planning each learning scenario needs to always keep in mind the nature of the material to be studied by students, student readiness factors, and student motivation to learn, because what students will learn must be aware of the meaning and benefits for students and for their future lives. Efforts to raise the motivation of class XI students of SMA Negeri 1 Natar South Lampung in learning mathematics have been carried out by teachers in their field of study in various ways, such as providing opportunities for students to ask questions, and designing learning in the form of group discussions. Based on the fact that $t$ arithmetic is between $t<t$ with a significant level of $5 \%$, the value of $t=$ $0.98<t=1.76$ so that Ho is accepted, the study shows that the average ability of students in the initial test of ability to learn mathematics has increased.
\end{abstract}

Keywords: Mathematics learning outcomes, contextual questions

\begin{abstract}
Abstrak
Proses pembelajaran melibatkan tiga komponen penting yaitu materi pelajaran, kegiatan pembelajaran dan penilaian (evaluasi). Merencanakan setiap skenario pembelajaran perlu selalu mengingat hakikat materi yang akan dipelajari siswa, faktor kesiapan siswa, dan motivasi siswa untuk belajar, karena apa yang akan dipelajari siswa harus disadari makna dan manfaatnya bagi sis-wa serta bagi kehidupannya kelak. Upaya untuk membangkitkan motivasi siswa kelas XI SMA Negeri 1 Natar Lampung Selatan dalam pembelajaran matematika sudah dilakukan guru bidang studinya dengan berbagai macam cara, seperti memberi kesempatan siswa untuk bertanya, serta mendesain pembelajaran dalam bentuk diskusi kelompok. Berdasarkan kenyataan $\mathrm{t}$ hitung berada di antara $\mathrm{t}_{\text {hit }}<\mathrm{t}_{\text {tabel }}$ dengan taraf significant $5 \%$ diperoleh harga $\mathrm{t}_{\text {hit }}=0,98<\mathrm{t}_{\text {tabel }}=1,76$ sehingga Ho diterima, maka penelitian menunjukkan bahwa kemampuan rata-
\end{abstract}




\section{Hipotenusa}

Journal of Research Mathematics Education VOL.3 NO.2 2020

rata siswa dalam tes awal kemampuan hasil belajar matematika mengalami peningkata.

Kata kunci: Hasil belajar matematika, soal kontekstual

\section{PENDAHULUAN}

Pedidikan adalah hal yang terpenting bagi kehidupan manusia. Dengan adanya pendidikan manusia menyerap pengalaman yang ada di sekitarnya, sehingga pendidikan terus bergerak megikuti perkembangan zaman, kemudian berbagai upaya pembenahan, diantaranya peningkatan profesional guru dan penyempurnaan kurikulum serta pedoman pelaksanaannya telah dilakukan oleh pemerintah. Akan tetapi, meskipun kemampuan propesional guru telah ditingkatkan dan kurikulum telah di-sempurnakan, namun keberhasilan proses pembelajaran tidak terlepas dari berbagai usaha pendidik yang melaksanakan di lapangan. Merunut Kurikulum Berbasis Kompetensi yang disempurnakan dalam Kurikulum Tingkat Satuan Pendidikan bahwa setiap individu mempunyai potensi yang harus dikembangkan, maka proses pembelajaran yang cocok adalah yang menggali potensi anak untuk selalu kreatif dan berkembang.

Pemberian masalah yang dikemukakan perlu diawali dari realitas kehidupan untuk ditarik dalam pemahaman konsep matematika, prinsip dan aturan matematika, selanjutnya diaplikasikan ke dalam konteks pemecahan masalah dalam kehidupan dengan menggunakan matematika. Hal ini merupakan inti yang dikembangkan dalam pembelajaran yang dikenal dengan istilah realitic mathematic. Namun pada kenyataannya belum menunjukkan ke arah pembelajaran yang bermakna. Para pendidik masih menyesuaikan dengan KTSP, kemudian para pendidik juga belum siap dengan kondisi yang sedemikian majemuk sehingga untuk mendesain pembelajaran yang bermakna masih mengalami kesulitan. Sistem pembelajaran dengan memposisikan siswa hanya duduk, mendengarkan pembelajaran dari guru sudah membudaya sejak dulu, sehingga guru 
mengalami kesulitan dalam menciptakan perubahan ke arah pembelajaran yang aktif, kreatif, dan menyenangkan.

Berdasarkan pengamatan awal terhadap proses pembelajaran matematika di SMA Negeri 1 Natar Lampung Selatan khususnya kelas XI diperoleh informasi bahwa selama proses pembelajaran, pendidik belum mengeluarkan seluruh potensi yang dimilikinya secara maksimal, sehingga sebagian besar siswa belum mampu mencapai kompetensi yang diperlukan untuk mengikuti pelajaran lebih lanjut. Terdapat beberapa siswa yang belum belajar sampai pada tingkat pemahaman. Siswa baru mampu menghafal konsep, prinsip, hukum, teori, dan gagasan inovatif lainnya pada tingkat ingatan, mereka belum mampu menggunakan dan menerapkannya secara efektif dalam pemecahan masalah secara kontekstual.

Upaya untuk menumbuhkan motivasi siswa kelas XI SMA Negeri 1 Natar Lampung Selatan dalam pembelajaran matematika sudah dilakukan guru bidang studinya dengan berbagai macam cara, seperti siswa diberikan kesempatan untuk bertanya, serta membentuk diskusi kelompok dalam proses pembelajaran. Namun hasil ulangan harian pada mata pelajaran Matematika semester I tahun pelajaran 2008/ 2009 masih belum begitu memuaskan. Hal ini dibuktikan pada ratarata nilai Matematika yang hanya 72,21 berada pada urutan ke-4 setelah Bahasa Indonesia (rata-rata 77,02), Ilmu Pengetahuan Alam (rata-rata 74,30), dan IPS (rata-rata 73,00).

Berdasarkan kondisi tersebut maka penulis tergerak untuk melakukan penelitian tin-dakan kelas dengan judul: "Penerapan Pemberian Latihan Soal-soal Kontekstual da-lam Meningkatkan Hasil Belajar Matematika pada siswa kelas XI SMA Negeri 1 Natar Lampung Selatan“.

\section{METODE PENELITIAN}

Penelitian ini bertujuan untuk mengetahui: (1) Pengaruh penerapan pemberian latihan soal-soal kontekstual dalam 


\section{Hipotenusa}

Journal of Research Mathematics Education

meningkatkan hasil belajar matematika pada siswa kelas XI semester genap SMA Negeri 1 Natar Kabupaten Lampung Selatan; (2) Rata-rata peningkatan hasil belajar matematika lebih baik setelah pemberian latihan soal-soal kontekstual pada siswa kelas XI semester genap SMA Negeri 1 Natar Kabupaten Lampung Selatan. Selanjutnya subjek dan lokasi penelitian ini adalah siswa kelas XI semester genap SMA Negei 1 Natar Lampung Selatan tahun pelajaran 2008/2009.

Penelitian ini menggunakan metode eksprimen yakni dengan melakukan langkah-angkah sebagai berikut:

1) Mengadakan pre-test untuk mengetahui kemampuan siswa dalam menyelesaikan soal-soal latihan sebelum diberikan latihan soal-soal kontekstual.

2) Mengevaluasi hasil jawaban pre-test dan mengelompokkannya sesuai sengan tingkat kemampuan siswa.

3) Mengidentifikasi kesalahan-kesalahan yang dilakukan siswa sesuai hasil pre-test.

4) Siswa diberikan tugas untuk menyelesaikan soal-soal latihan setelah diberi latihan soal-soal kontekstual

5) Mengevaluasi hasil pekerjaan siswa, dan mengelompokkannya.

6) Mengidentifikasi kembali kesalahan-kesalahan yang dilakukan siswa.

Teknik pengumpulan data yang digunakan dalam penelitian ini yaitu dengan cara pemberian tugas. Setiap siswa yang telah ditetapkan sebagai sampel diberikan tugas untuk menyelesaikan soal-soal latihan. Pemberian tugas dilakukan dua kali, yang pertama diberikan soal matematika tanpa pemberitahuan bentuk soal kontekstual, dan yang kedua menyelesaikan soal matematika dengan diberitahukan bentuk soal kontekstual. Selanjutnya untuk menganalisis data penelitian penulis menggunakan analisis statistik, oleh sebab itu data yang dikumpulkan adalah data kuantitatif atau data yang berupa angkaangka yang didapat dari hasil tes dan diberi nilai dari tiap-tiap sampel.

\section{Uji Normalitas Kelas Eksperimen}




\section{Hipotenusa}

Journal of Research Mathematics Education VOL.3 NO.2 2020

Berdasarkan kriteria uji $\chi_{\text {hit }}^{2} \leq \chi_{\text {tabel }}^{2}$ selain itu di tolak. Dari data pada kelas eksperimen dan kelas kontrol dipergunakan rumus:

1) Rentang nilai $(\mathrm{R}) \quad=$ data tertinggi - data terendah $=80-45=$ 35

2) Banyak kelas $(\mathrm{K}) \quad=1+3,3 \log \mathrm{n}=1+3,3 \log 36$

3) Panjang kelas interval ( $\mathrm{P})=\frac{R}{K}=\frac{35}{6}=6$ atau 7

4) Membuat tabel distribusi frekuensi mencari rata-rata dan simpangan baku dengan rumus sebagai berikut:

Tabel 1

Distribusi Frekuensi Kelas Eksperimen

\begin{tabular}{|c|c|c|c|c|c|}
\hline Interval & $\mathrm{F}_{\mathrm{i}}$ & $X_{i}$ & $X_{i}^{2}$ & $\mathrm{~F}_{\mathrm{i}} \mathrm{X}_{\mathrm{i}}$ & $\left(\mathrm{F}_{\mathrm{i}} \cdot \mathrm{X}_{\mathrm{i}}\right)^{2}$ \\
\hline $40-46$ & 2 & 43,5 & 1892,25 & $87,252,5$ & 3784,5 \\
\hline $47-53$ & 7 & 50,5 & 2550,25 & 353,5 & 17851,75 \\
\hline $54-60$ & 9 & 57,5 & 3306,25 & 517,5 & 29756,25 \\
\hline $61-67$ & 9 & 64,5 & 4160,25 & 580,5 & 37442,25 \\
\hline $68-74$ & 7 & 71,5 & 5112,25 & 500,5 & 35785,75 \\
\hline \multirow[t]{2}{*}{$75-81$} & 2 & 78,5 & 6162,25 & 157 & 12324,5 \\
\hline & 36 & & & 2196 & 136945 \\
\hline
\end{tabular}

Sumber : Pengolahan Data

$$
\begin{aligned}
& \bar{X}=\frac{\sum\left(F_{i} \cdot X_{i}\right)}{\sum F_{i}}=\frac{2196}{36}=61 \\
& S^{2}=\frac{n \cdot \sum F_{i} \cdot X_{i}-\left(\sum\left(F_{i} \cdot X_{i}\right)\right)^{2}}{n \cdot(n-1)}=\frac{36.136945-(2196)^{2}}{36.35} \\
& \mathrm{~S}^{2}=\frac{49300020-4822416}{1260}=\frac{107604}{1260}=85,4 \\
& \mathrm{~S}=\sqrt{85,4}=9,2
\end{aligned}
$$

5) Membuat Tabel Perhitungan Uji Nomalitas

Tabel 2

Uji Normalitas Kelas Eksperimen

\begin{tabular}{l|l|l|l|l|l}
\hline$X_{\mathrm{i}}$ & $\mathrm{Z}$ & $\mathrm{L}_{\mathrm{o}}$ & $\mathrm{L}_{\mathrm{i}}$ & $\mathrm{E}_{\mathrm{i}}$ & $\mathrm{O}_{\mathrm{i}}$ \\
\hline
\end{tabular}




\section{Hipotenusa}

Journal of Research Mathematics Education

\begin{tabular}{l|l|l|l|l|l}
\hline \multicolumn{2}{l|}{$-2,33$} & 0,4901 & & & \\
\hline 39,5 & $-1,57$ & 0,4418 & 0,0483 & 1,7388 & 2 \\
46,5 & $-0,81$ & 0,2910 & & & \\
53,5 & $-0,05$ & 0,0199 & 0,1508 & 5,4288 & 7 \\
60,5 & 0,70 & 0,2580 & & & \\
67,5 & 1,46 & 0,4279 & 0,2711 & 9,7596 & 9 \\
74,5 & 2,22 & 0,4868 & 0,2779 & 10,0044 & 9 \\
81,5 & & & 0,1699 & 6,1164 & 7 \\
& & & 0,0589 & 2,1204 & 2 \\
\hline
\end{tabular}

Sumber: Pengelahan Data

$$
\begin{aligned}
\chi^{2}= & \frac{(2-1,7388)^{2}}{1,7388}+\frac{(7-5,4288)^{2}}{5,4288}+\frac{(9-9,7596)^{2}}{9,7596}+\frac{(9-10,0044)^{2}}{10,0044}+\frac{(7-6,1164)^{2}}{6,1164} \\
& +\frac{(2-2,1204)^{2}}{2,1204}
\end{aligned}
$$

$\chi^{2}=0,039+0,455+0,059+0,1008+0,128+0,007=0,7888$

Untuk distribusi chi kuadrat besarnya derajat kebebasan (dk) adalah df $=\mathrm{K}-3=6-3=3$. Dalam tabel diperoleh $\chi_{0,99(3)}^{2}=11,3$, sesuai kriteria uji Terima $\mathrm{H}_{\mathrm{o}}$ jika $\chi_{\text {hit }}^{2} \chi_{\text {teb }}^{2}$. Jadi terbukti bahwa data nilai matematika siswa berasal dari kelas eksperimen yang berdistribusi normal.

\section{Uji Normalitas Kelas Kontrol}

Hipotesis:

$\mathrm{H}_{\mathrm{o}}=$ Data nilai matematika siswa dari kelas kontrol yang berdistribusi normal.

$\mathrm{H}_{\mathrm{i}}=$ Data nilai matematika siswa dari kelas kontrol yang tidak berdidtribusi normal.

Dengan Kriteria uji: Terima $\mathrm{H}_{\mathrm{o}}$ jika $\chi_{\text {hit }}^{2} \leq \chi_{\text {tab }}^{2}$ selain itu ditolak. Dari data itu kelas eksperimen skor tertinggi adalah 70 dan skor terendah 38, maka dapat dihitung dengan langkah-langkah sebagai berikut:

1) Rentang nilai ( $R$ ) $=70-38=32$

2) Banyak kelas $(\mathrm{K})=1+3,3 \log 36=1+5,136=6$

3) Panjang kelas ( P ) $=32 / 6=6$

4) Buat tabel Distribusi frekuensi mancari rata-rata hitung dan simpangan baku 
Tabel 3

Distribusi Frekuensi Kelas Kontrol

\begin{tabular}{l|l|l|l|l|l}
\hline Interval & $F_{i}$ & $X_{i}$ & $X_{i}^{2}$ & $F_{i} X_{i}$ & $F_{i} X_{i}^{2}$ \\
\hline $35-40$ & 2 & 37,5 & 1406,25 & 75 & 2812,5 \\
\hline $41-46$ & 7 & 43,5 & 1892,25 & 304,5 & 13245,75 \\
\hline $47-52$ & 8 & 49,5 & 2450,25 & 396 & 19602 \\
\hline $53-58$ & 8 & 55,5 & 3080,25 & 444 & 24642 \\
\hline $59-64$ & 7 & 61,5 & 3782,25 & 430,5 & 26475,75 \\
\hline $65-70$ & 4 & 67,5 & 4556,25 & 270 & 18225 \\
\hline & 36 & & & 1920 & 105003 \\
\hline
\end{tabular}

Sumber: Pengelahan Data

$$
\begin{aligned}
\bar{X} & =\frac{\sum F_{i} \cdot X_{i}}{\sum F_{i}}=\frac{1920}{36}=532 \\
S^{2} & =\frac{n \cdot \sum F_{i} \cdot X_{i}-\left(\sum F_{i} \cdot X_{i}\right)^{2}}{n \cdot(n-1)} \\
& =\frac{36 \cdot 105003-(1920)^{2}}{36 \cdot 35}=\frac{3780072-3686400}{1260}=74,34
\end{aligned}
$$

$\mathrm{S}=\sqrt{74,34}=8,6$

5) Membuat Tabel Perhitungan Uji Normalitas

Tabel 4

Perhitungan Uji Normalitas Kelas Kontrol

\begin{tabular}{l|l|l|l|l|l}
\hline $\mathrm{X}_{\mathrm{i}}$ & $\mathrm{Z}$ & $\mathrm{L}_{0}$ & $\mathrm{~L}_{\mathrm{i}}$ & $\mathrm{E}_{\mathrm{i}}$ & $\mathrm{O}_{\mathrm{i}}$ \\
\hline 34,5 & $-2,19$ & 0,4857 & \multicolumn{2}{l}{} \\
\hline 40,5 & $-1,49$ & 0,4319 & 0,0538 & 1,9368 & 2 \\
\hline 46,5 & $-0,79$ & 0,2852 & 0,1467 & 5,2812 & 7 \\
\hline 52,5 & $-0,09$ & 0,0359 & 0,2493 & 8,9748 & 8 \\
\hline 56,5 & 0,60 & 0,2257 & 0,2616 & 9,4176 & 8 \\
\hline 64,5 & 1,30 & 0,4032 & 0,1775 & 6,2900 & 7 \\
\hline 70,5 & 2,00 & 0,4772 & 0,0740 & 2,6640 & 4 \\
\hline
\end{tabular}

Sumber: Pengelahan Data

$$
\begin{aligned}
\chi^{2}= & \frac{(2-1,9368)}{1,9368}+\frac{(7-5,2812)}{5,2812}+\frac{(8-8,9748)}{8,9748}+\frac{(8-9,4176)}{9,4176}+ \\
& \frac{(7-6,2900)}{6,2900}+\frac{(4-2,6640)}{2,6640} \\
= & 0,002+0,56+0,11+0,21+0,06=1,612
\end{aligned}
$$

Dari daftar distribusi frekuensi dapat diketahui banyaknya kelas $(\mathrm{K})=$ 6 , untuk distribusi chi kuadrat besarnya derajat kebebasan (dk) adalah $\mathrm{df}=\mathrm{K}-3=6-3=3$. 


\section{Hipotenusa}

Journal of Research Mathematics Education

Dalam tabel diperoleh $\chi_{0,95(3)}^{2}=7,815$ dan $\chi_{0,99(3)}^{2}=11,3$ sesuai kreteria uji.

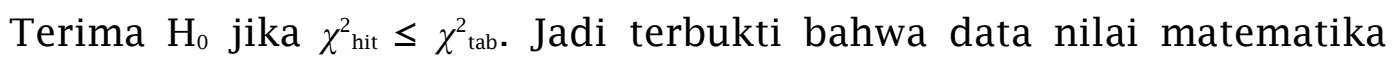
siswa berasal dari kelas control yang berdistribusi normal.

\section{Uji Homogenitas}

Dengan kriteria uji: Terima Ho jika $F_{\frac{1}{2} \alpha(d k 1, d k 2)}\left\langle F_{h i t}\right.$, dengan $F_{\frac{1}{2} \alpha(d k 1, d k 2)}$ didapat dari daftar tabel distribusi $\mathrm{F}$ dan peluang $\frac{1}{2} \alpha$, sedangkan derajat kebebasan dk 1 dan $\mathrm{dk} 2$ masing-masing sesuai dengan dk pembilang dan menyebut, dengan rumus

$F=\frac{\text { Variansterbesar }}{\text { Variansterkecil }}=\frac{85,4}{74,34}=1,149$

Dengan $\alpha=0,05$ diperoleh $\mathrm{F}_{\mathrm{tab}(35,35)}=1,74$ dan $\alpha=0,01$ diperoleh $\mathrm{F}_{\text {tab(35,35) }}$ $=2,21$.

Sesuai dengan criteria untuk $\alpha=0,05$ dan $\alpha=0,01$ diperoleh $\mathrm{F}_{\text {hit }}<\mathrm{F}_{\text {tab }}$, sehingga $\mathrm{H}_{\circ}$ diterima berarti data nilai matematika siswa memiliki varian yang homogen.

Setelah data terkumpul maka data dianalisis untuk dapat melakukan pengujian hipotesis:

Ha.1 : Ada pengaruh pemberian latihan soal-soal kontekstiual terhadap peningkatan hasil belajar matematika pada siswa kelas XI semester genap SMA Negeri 1 Natar Lampung Selatan tahun pelajaran $2008 / 2009$

Ha.2 : Rata-rata peningkatan hasil belajar matematika siswa setelah menerapkan la-tihan soal-soal kontekstual lebih tinggi dibandingkan sebelum menerapkan la-tihan soal-soal kontekstual pada siswa kelas XI semester genap SMA Negeri 1 Natar Lampung Selatan tahun pelajaran 2008/2009

Rumus statistik yang digunakan dalam penelitian ini adalah sebagai berikut : 


$$
\mathrm{t}_{\text {hitung }}=\frac{\bar{x}_{1}-\bar{x}_{2}}{S \sqrt{\frac{1}{n_{1}}}+\frac{1}{n_{2}}}
$$

dengan : $\mathrm{S}^{2}=\frac{\left(n_{1}-1\right) S_{1}^{2}+\left(n_{2}-1\right) S_{2}^{2}}{n_{1}+n_{2}-2}$

dimana :

$\bar{x}_{1}$ : Rata-rata hasil belajar matematika setelah penerapan pemberian latihan soal-soal kontekstual.

$\bar{x}_{2}$ : Rata-rata hasil belajar matematika sebelum penerapan pemberian latihan soal-soal kontekstual.

$\mathrm{n}_{1}$ : banyaknya siswa yang belajar sesudah penerapan pemberian latihan soal-soal kontekstual

$\mathrm{n}_{2}$ : banyaknya siswa yang belajar sebelum penerapan pemberian latihan soal-soal kontekstual

$S_{1}$ : Standar deviasi dari data sesudah penerapan pemberian latihan soal-soal kon-tekstual

$\mathrm{S}_{2}$ : Standar deviasi dari data sebelum penerapan pemberian latihan soal-soal kontekstual

$\mathrm{S}^{2}$ : Standar deviasi gabungan

(Sudjana, 1996; 239)

\section{Uji Kesamaan Dua Rata-Rata}

Uji hipotesis yang digunakan dalam penelitian ini adalah uji kesamaan dua rata-rata, pasangan hipotesisnya sebagai berikut :

Ho. $1: \mu_{1}=\mu_{2}$

(tidak ada pengaruh penerapan pemberian latihan soal-soal kontekstual terhadap peningkatan hasil belajar matematika)

Ho.2: $\mu_{1} \neq \mu_{2}$

(ada pengaruh teknik penerapan pemberian latihan soal-soal kontekstual terhadap peningkatan hasil belajar matematika)

Kriteria uji: 


\section{Hipotenusa}

Journal of Research Mathematics Education

Terima Ho. 1 ; jika $-\mathrm{t}_{(1-1 / 2 \alpha)}<\mathrm{t}<\mathrm{t}_{(1-1 / 2 \alpha)}$ selain itu Ho ditolak-t $(1-1 / 2 \alpha)=$ nilai t dari distribusi student dengan peluang $(1-1 / 2 \alpha), \alpha=$ taraf signifikan dan derajat kebebasan $(d b)=n_{1}+n_{2}-2$. (Sudjana, 1996; 239)

\section{Uji Perbedaan Dua Rata-Rata}

Menguji hipotesis penulis menggunakan uji dua rata - rata yang pasangan hipote-sisnya :

Ho. $1: \mu_{1} \leq \mu_{2}$

(Rata-rata peningkatan hasil belajar matematika dengan pemberian latihan soal-soal kontekstual lebih rendah atau sama denga rata-rata hasil belajar matematika dengan pemberian latihan soal-soal kontekstual)

Ha. $2: \mu_{1}>\mu_{2}$

(Rata-rata peningkatan hasil belajar matematika dengan pemberian latihan soal-soal kontekstual lebih tinggi dengan yang tidak diberikan latihan soal-soal kontekstual).

Kriteria uji :

Terima Ho. 2 , jika $\mathrm{t}<\mathrm{t}_{(1-\alpha)}$ selain itu Ho ditolak $\mathrm{t}_{(1-\alpha)}=$ nilai $\mathrm{t}$ dari daftar deviasi students dengan peluang $(1-\alpha), \alpha=$ taraf signifikan dan derajat kebebasan $(\mathrm{dk})=\mathrm{n}_{1}+\mathrm{n}_{2}-2 .($ Sudjana, 1996; 235)

\section{Pengacuan Pustaka}

Elaine B. J. PH.D, 2007: 57 menyatakan bahwa: Kontekstual adalah sebuah sistem yang merangsang otak untuk menyususn polapola yang mewujudkan makna. Kontekstual adalah suatu sistem pembelajarab yang cocock dengan otak yang meng-hasilkan makna 


\section{Hipotenusa}

Journal of Research Mathematics Education

dengan menghubungkan muatan akademis dengan konteks dari kehidupan sehari-hari siswa.Dengan memanfaatkan keyataan bahwa lingkungan merang-sang sel-sel saraf otak untuk membentuk jalan, sistem ini mefokuskan diri pada kon-teks, pada hubungan-hubungan.

Pembelajaran kontekstual menurut Herry Sukarman (2002: 13) adalah: pembelajaran yang menempatkan siswa di dalam konteks bermakna yang menghubungkan penge-tahuan awal siswa dengan materi yang sedang dipelajari dengan menekankan pada hal-hal:

1) Belajar berbasis masalah;

2) Pengajaran autentik;

3) Belajar berbasis inkuiri (pengalama atau penyelidikan);

4) Belajar berbasis proyek atau tugas terstruktur;

5) Belajar berbasis kerja;

6) Belajar jasa layanan;

7) Belajar kooperatif.

Karakteristik pembelajaran matematika yang kontektual meliputi (1) masalah yang dapat dibayangkan oleh siswa, karena sesuai dengan lingkungan kehidupan nyata siswa (kasat mata) atau sesuai dengan alam pikiran siswa, (2) harus berfokus pada matematika sebagai kegiatan siswa yang disebut proses matematisasi, (3) proses matematisasi horisontal atau matematika informal, (4) berlanjut ke proses mate-matisasi vertikal atau mempelajari matematika formal. (Herry Sukarman. M.Sc.Ed, dkk, 2002: 22).

\section{Pengertian Latihan Soal-soal Matematika}

Latihan soal atau sering disebut dengan pemberian tugas mempuyai banyak tujuan dan manfaat, salah satunya agar memacu adanya komunikasi antara siswa dan guru, siswa dengan siswa, dan hubungan lanjutan lain antara guru dengan orangtua siswa dan siswa dengan orangtua. Hubungan ini terbentuk jika tugas yang diberikan mempunyai kaitan dengan permasalahan siswa dalam belajar.

Syaiful Sagala H. (2005:219) mengatakan bahwa, teknik pemberian tugas latihan soal adalah cara penyajian bahan pelajaran 


\section{Hipotenusa}

Journal of Research Mathematics Education

di mana guru memberikan tugas tertentu agar murid melakukan kegiatan belajar, kemudian harus dipertanggungjawabkannya. Sedangkan menurut Udin Syaefudin (2005:52) mengatakan bahwa, teknik pemberian tugas merupakan suatu teknik pembelajaran dengan cara membagikan tugas-tugas kepada siswa. Berdasarkan kedua pendapat di atas penulis merujuk pada pendapat Syaiful Sagala yang menagatakan bahwa, teknik pemberian tugas adalah cara penya-jian bahan pelajaran di mana guru memberikan tugas tertentu agar murid melakukan kegiatan belajar, kemudian harus dipertanggung jawabkannya.

Metode pemberian tugas mempunyai beberapa kebaikan. Syaiful Sagala. H. (2005:219) menjelakan bahwa kebaikan pemberian tugas antara lain:

(1) pengetahuan yang diperoleh murid dari hasil belajar, hasil percobaan atau hasil penyelidikan yang banyak berhubungan dengan minat atau bakat yang berguna untuk hidup mereka akan lebih meresap, tahan lama dan lebih otentik; (2) mereka berke-sempatan memupuk perkembangan dan keberanian mengambil inisiatif, bertanggung jawab dan berdiri sendiri; (3) tugas dapat lebih meyakinkan tentang apa yang dipela-jari dari guru, lebih memperdalam, memperkaya atau memperluas wawasan tentang apa yang dipelajari; (4) tugas dapat membina kebiasaan siswa untuk mencari dan mengolah sendiri informasi dan komunikasi; (5) dapat membuat siswa bergairah da-lam belajar dilakukan dengan berbagai variasi sehingga tidak membosankan.

Berdasarkan pendapat di atas penulis berpendapat bahwa dengan adanya pemberian tugas dan latihan soal-soal dapat dijadikan barometer tercapai atau tidaknya pembelajaran setiap materi atau sub pokok bahasan yang diajarkan. Dengan memberikan latihan soal-soal secara kontekstual akan meningkatkan keinginan siswa untuk dapat mengatasi persoalan yang dihadapi sehari-hari yang berhubungan dengan matematika. 


\section{HASIL DAN PEMBAHASAN}

Berdasarakan hasil penelitian hipotesis dalam penelitian ini diterima. Peningkatan hasil belajar matematika siswa lebih tinggi setelah pemberian latihan soal-soal kontekstual daripada sebelum pemberian latihan soal-soal kontekstual. Data penelitian menunjukkan bahwa kemampuan rata-rata siswa dalam tes awal ke-mampuan hasil belajar matematika sebelum menerapkan latihan soal-soal kontekstual 61,51, kemampuan ini tergolong sedang. Setelah melaksanakan latihan soal-soal kontekstual maka kemampuan hasil belajar matematika siswa meningkat menjadi 65,15, kemampuan ini masih tergolong sedang, namun ada peningkatan sebanyak 65,15 - 61-51= 3,64 . Walaupun peningkatan ini masih tergolong sedang, namun dari selisih angka tersebut tergambar bahwa terdapat peningkatan yang jelas.

Berdasarkan hasil penelitian ini dapat disimpulkan bahwa dalam pembelajaran dengan pemberian latihan soal-soal kontekstual sebaiknya selalu menggunakan pendekat-an pada penyelesaian soalsoal yang kontekstual. Karena dengan latihan soal-soal kontekstual siswa akan terbiasa dengan pengalaman hidup sehari-hari yang sering dijumpai.

\section{KESIMPULAN DAN SARAN}

\section{Kesimpulan}

Berdasarkan uraian dan pembahasan di muka, dapat disimpulkan bahwa peningkatan hasil belajar matematika dapat ditingkatkan dengan pemberian latihan soal-soal kon-tekstual. Dari hasil penelitian ternyata peningkatan prestasi belajar matematika siswa dengan penarapan pemberian latihan soal-soal kontekstual lebih baik dari pada sebelum di terapkannya teknik pemberian latihan soal-soal kontekstual. Dalam bab IV ditunjukkan bahwa jelas perbedaan dua 


\section{Hipotenusa}

Journal of Research Mathematics Education

rata-rata ada perbedaan antara: $t_{\text {hitung }}$ dengan $t_{\text {tabel }}$. Sehingga dapat disimpulkan :

1. Terdapat pengaruh penerapan pemberian latihan soal-soal kontekstual ter-hadap peningkatan hasil belajar matematika, sebab dengan penerapan teknik tersebut dapat membantu siswa dalam proses memahami, menganalisa, dan menyimpulkan materi yang disajikan. Karena itu mereka tidak bosan untuk berlatih, lebih mandiri di dalam pengembangan kemampuan dalam menyelesaikan soal-soal matematika.

2. Rata-rata peningkatan hasil belajar matematika siswa yang belajar dengan pe-nerapan pemberian latihan soal-soal matematika yang kontekstual lebih tinggi dari pada belajar tanpa menerapkan pemberian latihan soal-soal matematika yang kontekstual.

\section{Saran}

Untuk meningkatkan hasil pembelajaran matematika disarankan :

1. Hendaknya siswa dibimbing dalam belajar dengan menerapkan pemberian la-tihan soal-soal matematika yang kontekstual.

2. Guru Matematika hendaklah selalu mengikuti pelatihan dan penataran-pena-taran untuk meningkatkan kemampuan, sehingga guru menguasai penerapan latihan soal-soal matematika yang kontekstual.

3. Agar siswa dan guru menemukan teknik belajar matematika yang menye-nangkan sehingga pelajaran matematika, khususnya matematika yang kon-tekstual lebih bervariasi.

\section{DAFTAR PUSTAKA}

Sudjana. 1996. Metode Statistika. Bandung: Sinar Baru Algasindo.

B.J. Elaine. Ph.D , 2007. Contextual Teaching and Learning, Bandung. Mizan Learning Center

Sukarman, Herry, 2003, Dasar-Dasar Didaktik dan Penerapannya Dalam Pembelajaran, Jakarta, Departemen Pendidikan Nasional, Dirjen Dikdasmen, Direktorat Tenaga Kependidikan. 


\section{Hipotenusa}

Journal of Research Mathematics Education

VOL.3 NO.2 2020

e-ISSN: $2723-486 X$

p-ISSN: 2621-0630

Syaiful Sagala, 2005. Konsep dan Makna Pembelajaran Untuk Membantu Memecahkan Problematika Belajar dan Mengajar. Bandung: Alfabeta.

Saud. Udin Syaefudin dkk. (2005). Total Quality Manajement dalam Konteks Pendidikan. Bandung: Prodi Adpen UPI. 